\title{
The Relationship Between Oxytocin Level and Postpartum Depression
}

\section{Oksitosin Düzeyi ile Postpartum Depresyon Arasındaki İlişki}

\author{
Ayseren ÇEVIK ${ }^{1}$, Sultan ALAN
}

\begin{abstract}
Psychological and social changes during pregnancy, birth and postpartum periods may lead to the development of mental disorders. Postpartum depression is the most common psychological disorder seen in the postpartum period, and the treatment of it is very significant for the mother and the baby. Physical/biological, psychological, obstetric, pediatric and socio-economic status, genetic factors and hormonal changes are the risk factors of postpartum depression. Causing attachment, mental health and behavioral effects as well obstetric effects, oxytocin hormone is substantially crucial in postpartum depression. It is reported in the literature that there is a relationship between oxytocin level and postpartum depression. It is thought that usage of oxytocin levels as a predictive biomarker will offer an opportunity early diagnosis and treatment of postpartum depression, and will be a useful approach to minimize its impacts on family health.
\end{abstract}

Keywords: Oxytocin, postpartum depression, relationship between oxytocin and postpartum depression, pregnancy depression

\section{ÖZET}

Gebelik, doğum ve doğum sonrası dönemlerde fizyolojik, psikolojik ve sosyal yönden yaşanan değişimler, mental bozuklukların gelişmesine yol açabilmektedir. Doğum sonu dönemde en sık görülen, tedavi edilmesi anne ve bebek açısından oldukça önem taşıyan psikolojik rahatsızlık, postpartum depresyondur. Fiziksel/biyolojik, psikolojik, obstetrik, pediatrik ve sosyo-ekonomik durum, genetik etmenler ve hormonal değişimler postpartum depresyon için risk faktörleridir. Oksitosin hormonu, obstetrik etkilerinin yanı sıra bağlanma, mental sağlık ve davranışsal etkilere neden olduğu için, postpartum depresyonda oldukça önemlidir. Literatürde oksitosin düzeyi ile postpartum depresyon arasında bir ilişki olduğu bildirilmektedir. Oksitosin seviyelerinin prediktif bir biyobelirteç olarak kullanılmasının, erken tanı ve tedaviye olanak sunarak, postpartum depresyonun aile sağlığı üzerindeki etkilerini en aza indirme konusunda faydalı bir yaklaşım olacağı düşünülmektedir.

Anahtar Kelimeler: Oksitosin, postpartum depresyon, oksitosin ile postpartum depresyon ilişkisi, gebelik depresyonu

Received / Geliş tarihi: 08.06.2020, Accepted / Kabul tarihi: 18.10.2020

${ }^{1}$ Çukurova Üniversitesi Sağlık Bilimleri Enstitüsü Ebelik Anabilim Dalı

${ }^{2}$ Çukurova Üniversitesi Sağlık Bilimleri Fakültesi Ebelik Bölümü

*Address for Correspondence / Yazışma Adresi: Ayseren ÇEVIK, Çukurova Üniversitesi Sağlık Bilimleri Enstitüsü Ebelik Anabilim Dalı, Adana TÜRKIYE, E-mail: ayseren01.cevik@gmail.com

Çevik A, Alan S. The Relationship Between Oxytocin Level and Postpartum Depression. TJFMPC, 2021;15(1): 164-169.

DOI: $10.21763 / \mathrm{tjfmpc} .749563$ 


\section{Gİiș}

Postpartum depresyon, ele alınması gereken konulardan biridir. Fiziksel, biyolojik, psikolojik, obstetrik, pediatrik ve sosyo-ekonomik durumlar, postpartum depresyon için risk faktörleri olarak bilinmektedir. ${ }^{1}$ Depresyonun gelişiminde hormonal değişimlerin rolü büyüktür. Hormonal değişimlerin en sık yaşandığı gebelik, doğum ve doğum sonu dönemler, bu açıdan oldukça önem taşımaktadır. Bu dönemlerde, özellikle oksitosin düzeyinde önemli değişimler meydana gelmektedir., ${ }^{2,3}$

Obstetrik, mental sağlık ve davranışsal etkilere sahip kompleks bir hormon olan oksitosin, kişilerarası ilişkilerde bağlanma ve güven konusunda önemli bir rol oynamaktadır. ${ }^{4-8}$ Literatürde oksitosin düzeyi ile postpartum depresyon arasında bir ilişki olduğu bildirilmektedir. ${ }^{8-12}$ Gebelik dönemindeki oksitosin düzeyi, postpartum depresyonu öngören bir biyobelirteç olarak görülmektedir.

Bu derleme, oksitosin düzeyi ile postpartum depresyon semptomları arasındaki ilişkiyi incelemek amacıyla yapılmıştır. Özellikle gebelik döneminde oksitosin düzeyinin ölçülmesi, postpartum depresyon riskinin öngörülmesini sağlayarak kadınlara erken tanı ve tedavi imkânları sunabilecektir. Böylece postpartum depresyonun kadın, bebeği ve ailesi üzerinde yaratacağı olumsuz etkiler en aza indirilebilecektir. Postpartum dönemde kadınların mental sağlıklarının sürdürülmesi sağlandığında, nitelikli annelik deneyimi yaşamalarına katkı sağlanmış olacaktır.

\section{Kadın Yaşam Dönemleri ve Mental Sağlık}

Kadın, intrauterin dönemden, yaşlılık döneminin sonuna kadar birçok yaşamsal evrelerden geçmektedir. Bu evrelerin her birinde fiziksel, ruhsal ve sosyal değişimler yaşamaktadır. $\mathrm{Bu}$ yaşam döngülerinde kadında meydana gelen değişimler, kardiyovasküler ve sistemik hastalıkların yanı sıra psikiyatrik hastalıklara olan yatkınlığı da artırabilmektedir. ${ }^{1,13,14}$

Dünya Sağlık Örgütü (DSÖ), sağlığ1, "sadece hastalık veya sakatlığın olmaması değil aynı zamanda fiziksel, ruhsal ve sosyal açıdan tam bir iyilik halidir" şeklinde tanımlamaktadır. Mental sağlık ise kişisel iyi oluş hali, algılanan öz-yeterlilik, otonomi/özerklik, yetkinlik, nesiller arası bütünlük, entelektüel ve duygusal potansiyeli anlama yeteneğine sahip olmayı kapsamaktadır. İlaveten mental sağlik, stresle baş edebilme, üretken olma ve verimli çalışma gibi yetenekleri de içermektedir. ${ }^{15}$

Kadın yaşam döngülerinde en önemli dönemler arasında gebelik, doğum ve doğum sonrası dönemler yer almaktadır. Gebelik, doğum ve doğum sonrası dönem her ne kadar doğal bir süreç olarak kabul edilse de, kadınlar için stres faktörü oluşturabilmektedir. Oluşan bu stres faktörleri de, hassasiyeti veya genetik yatkınlığı olan kadınların bu döneme uyum sağlamasını güçleştirmekte ve kadınlarda mental bozukluklar gelişebilmektedir. $\mathrm{Bu}$ dönemlerde en sık yaşanan mental bozukluklardan biri depresyondur. ${ }^{1,13,14}$

Depresyon; bunalım hali, ilgi veya memnuniyet azlığı, azalmış enerji, suçluluk duygusu, uyku ve iştah bozukluğu ile seyreden, yaygın olarak görülen mental bir bozukluktur. ${ }^{16}$ Melankolik, atipik, psikotik, mevsimsel, kronik ve postpartum depresyon olmak üzere alt tipleri bulunmaktadır. ${ }^{17,18}$ Depresyon, en s1k görülen psikiyatrik hastalıklardan birisi olarak klinik bir öneme sahiptir. Dünyadaki depresyonlu kişi sayısı 322 milyondur. Kadınlarda, erkeklere kıyasla depresyon görülme sıklığı iki kat daha fazladır. Bu farklılığın sebebi kesin olarak bilinmemekle birlikte, endokrin sistemin neden olabileceği düşünülmektedir. Literatüre göre depresyonun kadınlarda görülme sıklığ1 \%10-20 arasındadır. ${ }^{17,19}$ Yaş, cinsiyet, kültürel farklılıklar gibi faktörler, depresyonun görülmesinde etkili olabilen faktörlerdir. Sosyo-ekonomik ve eğitim durumunun düşük olması, düzensiz veya dağılmış aile, genetik, nörokimyasal maddeler, hormonlar ve psikolojik etkenler gibi durumlar depresyon için risk faktörü oluşturabilmektedir. ${ }^{19}$ Depresyonun, biyolojik farklılıklar, beynin yapısı (nörotransmiterler), hormonlar (gebelik, doğum, menopoz dönemleri gibi), kalıtsal özellikler gibi durumlarla ilişkili olarak geliştiği gösterilse de, kesin nedeni henüz bilinmemektedir. ${ }^{8,10}$ Depresyon; duygu durumunda değişiklik, üzüntülü olma, çaresizlik ve yalnızlık hissi, kendini suçlama ve cezalandırma, ölme arzusu, yeme, uyku ve libido bozuklukları, aktivite durumlarında değişim (hareket ve konuşmalarda yavaşlama, ajitasyon) gibi klinik bulgular ile kendisini göstermektedir. Bu semptomlar, hafif düzeyden şiddetli düzeye doğru ilerleme gösterebilmektedir. ${ }^{19}$

\section{Oksitosin Hormonunun Mental Sağlık Üzerine Etkisi}

Nörohipofizeal hormon olan oksitosin ve arginin vazopresin (Antidiüretik hormon / $\mathrm{ADH}$ ), sadece farklı iki amino asit ile birbirinden ayrilan siklik nonapeptitlerdir. Oksitosin, hipotalamusun paraventriküler çekirdeklerindeki nöronlarda üretilen ve aksonlarında salgılanan arka hipofiz veya nörohipofizdeki nöronların aksonlarında depolanan nöropeptit hormondur. Nöral olmayan birkaç oksitosin kaynağı da (adrenal medulla, plasenta, korpus luteum, timüs, retina, pankreas, osteoblast ve 
testislerin Leyding interstitial) hücrelerinde bulunmaktadır. ${ }^{1-22}$

Oksitosin, kişilerarası ilişkilerde bağlanma ve güven konusunda önemli bir rol oynamaktadır. ${ }^{8}$ Yapılan bir çalışmada okstiosinin eşler arasında bağlanmayı kolaylaştırdığı öne sürülmektedir. Ayrıca sarılma ile oksitosin seviyesi arasında olumlu bir ilişki olduğu bildirilmektedir. Eşlerin birbirlerine iyi davranması ile daha yüksek oksitosin seviyeleri arasında güçlü bir ilişki olduğu vurgulanmaktadır. ${ }^{23}$ Oksitosin salınımı ile stres, anksiyete, kalp atım hızı, kan basincı düzeylerinde azalma meydana gelmektedir. $\mathrm{Bu}$ bakımdan oksitosinin nörofizyolojisi, potansiyel obstetrik etkilerinin yanı sıra, mental sağlık ve davranışsal etkileri sebebiyle klinik olarak bir öneme sahiptir. ${ }^{4-6}$

Yapılan bir araştırmada, depresyon ve Hipotalamus-hipofiz-adrenal (HPA) axis aktivitesi arasında iki farklı ilişki olduğu düşünülmektedir. HPA axis aktivitesine dair ilk görüş; beyinde fazla miktarda salınan kortizol etkisi üzerinedir. Depresif semptomların da bu mekanizma etkisi ile ortaya çıktığ 1 düşülmektedir. İkinci görüş ise, ilk görüşün tam tersidir. HPA axis aktivitesi; beyindeki kortizol sirkülasyonuna direnç gösterdiği için kompanzasyon mekanizması geliştiği düşünülmektedir. ${ }^{24}$

Gebelik, doğum ve doğum sonu dönemde, oksitosin hormon düzeyinde önemli değişim meydana gelmektedir. Oksitosin düzeyi, gebeliğin 35. haftasından postpartum dönemin 6. ayına kadar artış göstermektedir. Doğum ve emzirme süresince, sosyal etkileşimler sırasında, meme ucu stimülasyonu, bebeği kucaklama, sevme ve dokunma gibi davranışlar sonucunda da oksitosin düzeyi artmaktadır. ${ }^{3,17}$ Annelik ve sevgi hormonu olarak bilinen oksitosin hormonunun, annelik davranışı sergileme konusunda oldukça önemli bir yere sahip olduğu düşünülmektedir. ${ }^{25}$ Gebelik başlangıcında, gebelerin anksiyete düzeylerinde azalmanın oksitosin artışına bağlı geliştiği düşünülmektedir. Bu dönemde artmış oksitosin ile postpartum maternal davranışlar (bakma, konuşma, dokunma vb.) arasında ilişki olduğu bildirilmektedir. ${ }^{18,26}$

Gebelikte yüksek oksitosin düzeyleri, düşük oksitosin düzeylerine kıyasla, pozitif annelik davranışları, uzun dönem emzirme, güvenli bağlanma gibi durumları öngörmektedir. Ayrıca artmış oksitosin, postpartum dönemde üç ay emzirmenin öngörülmesine ve erken PPD riskinin azalmasına katkı sağlamaktadır. ${ }^{12,26}$

\section{Postpartum Dönem ve Mental Sağlık}

Maternal mental bozukluklar, anksiyete ve panik bozuklukları, posttravmatik stres bozukluğu, obsesif kompulsif bozukluk, depresyon ve psikoz şeklinde ele alınmaktadır. Postpartum dönemde annelik hüznü (postpartum hüzün), annelerin \%50-80'inde görülebilmektedir. Anksiyete, ağlama nöbetleri, uykusuzluk gibi durumların yaşandığı da bulgular arasında yer almaktadır. Postpartum hüzün, doğumdan 2-3 gün sonra meydana gelmekte ve tedavi gerektirmeden yaklaşık iki hafta içerisinde kendiliğinden geçmektedir. Postpartum depresyonla semptomları benzerlik gösterse de bu yönüyle postpartum depresyondan ayrılmaktadır. ${ }^{1,27}$ Doğum sonu dönemde en sık görülen, tedavi edilmesi anne ve bebek açısından oldukça önem taşıyan psikolojik rahatsılık postpartum depresyondur. ${ }^{1,27}$

\section{Postpartum Depresyon (PPD)}

Postpartum depresyon (PPD), semptomları, doğum sonu dönemin ilk 2-4. haftalarında görülmeye başlayan ve bir yıla kadar devam edebilen, klinik seyre sahip mental bir bozukluk şeklinde tanımlanmaktadır. ${ }^{27}$ Fiziksel, biyolojik, psikolojik, obstetrik, pediatrik ve sosyo-ekonomik durumlar PPD için risk faktörleri olarak bilinmektedir. ${ }^{1}$

Fiziksel ve Biyolojik Etmenler: Fiziksel sağlıkta bozulma veya hastalık, $20 \mathrm{~kg} / \mathrm{m}^{2}$ 'nin altında vücut kitle indeksi veya obezite, düşük beden algıs1 vb. gibi durumlar, PPD için risk faktörü olarak görülmektedir. ${ }^{1}$

Psikolojik Etmenler: Düşük benlik algısı, stresli gebelik, zayıf sosyal ve emosyonel destek, çocuk bakım stresi, aile sorunları, geçirilmiş depresyon öyküsü, ailede psikolojik hastalık öyküsü, gebeliğe karşı olumsuz tutum vb. gibi durumlar, PPD için risk faktörü olarak görülmektedir. ${ }^{1,2,27}$

Obstetrik ve Pediatrik Etmenler: Obstetrik komplikasyonlar, preterm eylem, emzirmeye başlama ve süresinde azalma, düşük doğum ağırlıklı yenidoğan, emzirme sorunları, planlanmamış gebelik, bebek bakımında bilgisizlik vb. gibi durumlar, PPD için risk faktörüdür. 1,2,27

Sosyo-ekonomik ve Diğer Etmenler: Düşük eğitim düzeyi ve sosyoekonomik durum, yaş, rrk, madde kullanımı, işsizlik, göç, aile içi şiddet vb. gibi durumlar, PPD için risk faktörüdür. 1,2,27,29

Hem anne hem de bebek sağlığını olumsuz yönde etkileyen PPD, en s1k görülen doğum komplikasyonlarından biridir. Dünyada postpartum depresyon görülme sıklığına bakıldığında, kadınların \%10-15'ini etkilediği görülmektedir. Gelişmiş ülkelere kıyasla, gelişmekte olan ülkelerde PPD görülme sıklığı daha fazladır. Asya ülkelerinde PPD görülme sıklığ $\%$ 6-13 arasındadır. Türkiye'de ise $\mathrm{bu}$ oran \%15.4-51.3 arasında değişiklik göstermektedir. $2,30,31$ 
PPD'nin nedeni henüz tam olarak bilinmemektedir. Genetik etmenler, hormonal değişimler, hipotalamik-pituater-adrenal aksın ve nörotransmitter, kolesterol ve yağ asidi anormalliklerin postpartum depresyon üzerine etkisinin olabileceği düşünülmektedir. . $^{3,9-11}$

PPD, kendini değersiz hissetme, anksiyete, panik ataklar, suçluluk, bebek ile ilgili endişeler, ağlamaklı hal, kontrolsüzce ağlama, konuşma ve hareket yavaşlığı, ajitasyon ya da hiperaktivite, yeme ve uyku bozuklukları, duygu ve düşünce karışıklığı, unutkanlık, öfkelenme, ölüm ve intihar düşünceleri, konsantrasyon, karar verme yeteneğinde ve cinsel aktivitelerde azalma gibi semptomlar ile seyretmektedir. ${ }^{1,32}$

\section{Oksitosin Düzeyi ile Postpartum Depresyon Arasındaki İlişki}

HPA ve amigdala aktivitesi sosyal stres üzerinde olumsuz bir etkiye sahiptir. Oksitosin salınımının, amigdala ve HPA aktivitesini azalttığı için, anksiyete azaltma, ruh hali ve sosyal stresi iyileştirmede anksiyolitik bir etkisinin olduğu düşünülmektedir. Eapen, vd. (2014), yaptıklar1 çalışmada, oksitosinin, Amigdala ve HPA (Hypothalamic-Pituitary-Adrenal) aktivitesini azalttığ için anksiyete azaltmada, ruh hali ve sosyal stresi iyileştirmede anksiyolitik bir etkisinin olduğunu vurgulamaktadırlar. ${ }^{33}$ Yapılan diğer bir çalışma ise düşük oksitosin seviyesinin, zayıf bağlanma ve maternal davranışlar, postpartum depresyon, kokain bağımlılığı, artmış stres ile ilişkisinin olduğunu göstermiştir. ${ }^{34}$ Güvenli bağlanma, aşırı strese yanıt olarak HPA aktivasyonuna karşı bir tampon görevi görmektedir. ${ }^{33}$ Erken bağlanma, postpartum dönemde anne ve bebeğe olumlu katkılar sağlayan bir durumdur. Anne-bebek bağlanmasında, oksitosinin rolü büyüktür. Maternal merkezi sinir sisteminde doğum öncesi, doğum ve doğum sonrası dönemde bazı fizyolojik hazırlıklar olmaktadır. Oksitosin, beta-endorfinler gibi hormonların düzeyinde artışlar meydana gelmektedir. $\mathrm{Bu}$ hormonlar da, anne-bebek arasındaki bağlanma ve iletişime, emzirmeye, yenidoğan bakımı ve annelik adaptasyonuna, sosyal iletişime, anksiyetenin ve suça yönelimin azalmasına yardımcı olmaktadır. Güvenli bağlanma, yenidoğan üzerinde uzun dönem etkilere sahiptir. Çocukluk ve yetişkinlik döneminde sağlık ve iyi olma durumunu etkilemektedir. ${ }^{26,33}$ Güvensiz bağlanan yenidoğanlarda bu tampon etkisi oluşmamaktadır. Bu durum ise depresyon ve diğer psikiyatrik hastalıklara yatkınlığı artırabilmektedir. Güvensiz bağlanma annede, stres ile başa çıkmada zorlanma, depresif ruh hali ve düşük oksitosin seviyeleri gibi durumlar gelişebilmektedir. Güvenli bağlanma ve emzirme, maternal oksitosin seviyelerini arttırdığ halinde azalmaya katkıda bulunmaktadır. ${ }^{33}$

Emzirme, anne ile bebek arasındaki duygusal bağlanmayı güçlendiren annelik hassasiyeti davranışlarına katkıda bulunmaktadır. Bebeğini sadece anne sütü ile besleyen anneler, formül mama ile besleyenlere k1yasla bu konuda daha hassas olabilmektedir. Bebeğinin ağlama sesini duyan annelerin hipotalamuslarındaki değişimleri karşılaştıran bir çalışma, emziren kadının hipotalamusunda daha fazla aktivasyon görüldüğünü bildirmektedir. ${ }^{34}$ Emzirme sirasında artan oksitosin seviyeleri annelerin, anksiyete düzeylerini azaltırken, sakinlik ve sosyal bağlanma isteklerini artırmaktadır. ${ }^{26}$

Psikolojik faktörler ve gebelik süreci PPD etyolojisi ile yakından ilgilidir. Erken postpartum dönem, emosyonel duyarlılık, endokrinolojik homeostazın bozulmasına yol açmaktadır. ${ }^{18}$ Literatürde oksitosin düzeyinin düşük olması ile postpartum depresyon arasında bir ilişki olduğu bildirilmektedir. $^{8-12}$ Jobst, vd. (2016), yaptıklar1 çalışmada, postpartum depresyon semptomları mevcut olan kadınların, gebeliğin 38. haftasından doğum sonrası ikinci güne kadar, semptom olmayan kadınlara kıyasla daha düşük oksitosin seviyelerine sahip olduklarını belirtmektedirler. ${ }^{3}$ Gebeliğin geç dönemlerinden postpartum dönemin 8 . haftasına kadarki süreçte kadınların ruh halleri ile oksitosin düzeyleri arasındaki ilişki değerlendirildiğinde ise emzirme süresince oksitosin düzeyi düşük olan kadınların, yüksek olanlara kıyasla daha fazla anksiyete ve depresyon yaşadığ ${ }_{1}$ anlaşılmaktadır. ${ }^{21,34}$ Skrundz, vd. (2011), yaptıkları çalışmada, gebelik döneminde artmış oksitosinin, postpartum dönemde üç ay emzirmenin öngörülmesine, erken postpartum depresyon riskinin azalmasına katkı sağladığını belirtmektedirler. ${ }^{9}$ Prevost, vd. (2014) yaptıkları çalışmada, gebelikte yüksek oksitosin düzeylerinin, düşük oksitosin düzeylerine kıyasla pozitif annelik davranışları, uzun dönem emzirme, güvenli bağlanma gibi durumlar öngörmektedirler. ${ }^{12}$ Ancak, bu durumu etkileyen başka faktörler de bulunmaktadır. Cinismo, vd. (2018), yaptıkları çalışmada, travmatik öyküsü bulunan, son zamanlarda stresli olay yaşayan ve istismar gibi durumlara maruz kalan kadınların, oksitosin seviyelerinin daha düşük, anne-bebek bağlanmalarının daha az, anksiyetelerinin ise daha fazla olduğunu dile getirmektedirler. ${ }^{11}$

\section{SONUÇ ve ÖNERILER}

Kadın sağlığı üzerine yoğunlaşmış postpartum bakım hizmeti, kadınların fizyolojik ve psikolojik sağlığını olumlu etkilemektedir. ${ }^{35}$ Postpartum dönemde ele alınması gereken konulardan birisi, postpartum depresyondur. Kadının mental sağlığını 
postpartum dönemde sürdürmek, esas hedefler arasındadır. Bu bakımdan, postpartum depresyonu öngören faktörler önemlidir. Yapılan çalışmalar, düşük oksitosin düzeyi ile postpartum depresyon arasında ilişki olduğunu göstermektedir. Ancak, oksitosinin postpartum depresyon tanısinda kullanılabilmesi için daha fazla çalışmaya ihtiyaç duyulmaktadır. Klinik olarak onaylandıktan sonra oksitosin seviyelerinin, gebeliğin son trimesterinde ölçülmesi, postpartum depresyon tanısında prediktif bir biyobelirteç olarak kullanılabilecektir. Bu uygulama ile PPD riski olan kadınlara erken tanı ve tedavi firsatı sunulabilecektir. Böylece, postpartum dönemde kadın ve ailesinin mental sağlığının sürdürülmesine ve daha nitelikli annelik deneyimi yaşamalarına olanak sağlanmış olacaktır. Gebelik döneminde oksitosin ölçümünün yanı sıra, gebelerin antenatal eğitim sınıfına katılmaları, bu eğitimlerde postpartum depresyon konusuna da yer verilmesi, kadınların sosyal desteklerinin artırılması, sağlıklı beslenme ve stresle baş etme yöntemleri ve bebek bakımı hakkında kadınların bilgilendirilmesi önerilmektedir. Ancak, tüm bu uygulamalar, kadınların kişilik özellikleri ve yaşam şartları göz önünde bulundurularak yapılmalıdır. Birinci basamak sağlık hizmetlerinde çalışan hekim, ebe ve hemşireler lohusa izlemlerinde kilit rol oynamaktadır. $\mathrm{Bu}$ birimde çalışan sağlık profesyonellerinin, postpartum depresyon konusunda bilinçlendirilmesi ve farkındalık oluşturulması önemlidir. Bu bakımdan, postpartum depresyon açısından riskli grupta olan kadınlara uygun danışmanlığın yapılması büyük önem taşımaktadır. ${ }^{36,37}$

\section{Çıkar Çatışması}

Yazarlar arasında herhangi bir çıkar çatışması bulunmamaktadır.

\section{Finansal Destek}

Araştırma için herhangi bir kurumdan finansal destek alınmamıştır.

\section{KAYNAKLAR}

1. Kolukırık Ü. Postpartum depresyon belirtisini etkileyen etmenler ve postpartum depresyon belirtisinin emzirme ile ilişkisi (Yayınlanmamış Uzmanlık Tezi). Dokuz Eylül Üniversitesi Tıp Fakültesi Halk Sağlığı Anabilim Dalı, İzmir, 2016. p. 5-20.

2. Azad R, Fahmi R, Shrestha S, Joshi H, Hasan M, Khan ANS, et al. Prevalence and risk factors of postpartum depression within one year after birth in urban slums of Dhaka, Bangladesh. PLoS One 2009;14(5): e0215735. Doi: 10.1371/journal.pone.0215735

3. Jobst A, Krause D, Maiwald C, Härtl K, Myint AM, Kästner R, et al. Oxytocin course over pregnancy and postpartum period and the association with postpartum depressive symptoms.
Arch Womens Ment Health 2016;19:571-579. Doi: 10.1007/s00737-016-0644-2

4. Erickson EN. Physiologic function ofoxytocin after birth: Influence on postpartum blood loss and lactation. OHSU Digital Collections 2018. Doi: 10.6083/GJ0W18

5. Cunningham FG, Leveno KJ, Bloom SL, Spong CY, Dashe JS, Hoffman BL, et al. Williams Obstetrics. 24th ed. MCGraw-Hill Education;2014 p. 46-72.

6. Gabbe S, Niebly JR, Simpson JL, Landon MB, Galan HL, Jauniaux ERM, et al. Obstettrics. 7th ed. Elsevier;2017. p. 38-60.

7. Demir E. Gebe Siçanlarda Oksitosin Hormonunun Pelvik Taban Kasları Üzerine Etkisinin İncelenmesi (Yayınlanmamış Yüksek Lisans Tezi). Çukurova Üniversitesi Sağlık Bilimleri Enstitüsü Ebelik Anabilim Dalı, Adana, 2019. p. 9-10.

8. De Cagna F, Fusar-Poli L, Damiani S, Rocchetti M, Giovanna G, Mori A, et al. The role of intranasal oxytocin in anxiety and depressive disorders: A systematic review of randomized controlled trials. Clinical Psychopharmacology an Neuroscience 2019;17(1):1-11.

9. Skrundz M, Bolten M, Nast I, Hellhammer DH, Meinlschmidt G. Plasma oxytocin concentration during pregnancy is associated with development of postpartum depression. Neuropsychopharmacology 2011;36(9):1886. Doi: $10.1038 / n p p .2011 .74$

10. Lara-Cinisomo S, McKenney K, Di Florio A, Meltzer-Brody S. Associations between postpartum depression, breastfeeding, and oxytocin levels in Latina mothers. Breastfeeding Medicine 2017;12:7. Doi: 10.1089/bfm.2016.0213

11. Lara-Cinisomo S, Zhu K, Fei K, Bu Y, Weston AP, Ravat U. Traumatic events: exploring associations with maternal depression, infant bonding, and oxytocin in Latina mothers. BMC Women's Health 2018;13:31. Doi: 10.1186/s12905-018-0520-5

12. Prevost M, Zelkowitz P, Tulandi T, Hayton B, Feeley N, Carter CS, et al. Oxytocin in pregnancy an the postpartum: relations to labor and its management. International Journal of Child Health and Human Development 2014;2(1). Doi: 10.3389/fpubh.2014.00001

13. Duman BU. Postpartum depresyon, eş desteği ve duygu düzenleme güçlükleri arasındaki ilişki (Yayınlanmamış Yüksek Lisans Tezi). Maltepe Üniversitesi Sosyal Bilimler Enstitüsü Psikoloji Anabilim Dalı, İstanbul, 2019. p. 2-9.

14. Taşkın, L. Doğum ve Kadın Sağlığı Hemşireliği. 12. Baskı, Ankara: Akademisyen Tip Kitabevi; 2014. p. 483-490.

15. WHO. (https://apps.who.int/iris/bitstream/handle/10665/ 42823/9241562579.pdf? sequence $=1$ \&isAllowed $=$ y) adresinden 17.06.2020 tarihinde erişilmiştir.

16. WHO (2012). (https://www.who.int/mental_health/management 
/depression/who_paper_depression_wfmh_2012. pdf) adresinden 17.06.2020 tarihinde erişilmiştir.

17. Tuman TC. DSM-5 Kriterlerine göre tanı konan depresyon, yaygın anksiyete bozukluğu, sosyal anksiyete bozukluğu ve panik bozukluk hastalarında serum oksitosin düzeylerinin sağlıklı kontrollerle karşılaştırılması (Yayınlanmamış Tipta Uzmanlık Tezi). Abant İzzet Baysal Üniversitesi Tip Fakültesi Ruh Sağlığı ve Hastalıkları Anabilim Dalı, Bolu, 2015. p. 11-51.

18. Sertçelik, S. Depresyon. Haydarpaşa Numune Eğitim Araştırma Hastanesi Psikiyatri Kliniği. (2013).

(http://www.istanbulsaglik.gov.tr/w/sb/per/belge/ depresyon_2013.pdf) adresinden 17.06.2020 tarihinde erişilmiştir.

19. Türen E. Prenatal anne-bebek bağlanmasında maternal oksitosin, kortizol ve prolaktin düzeylerinin etkisi ve annenin depresyon, anksiyete ve stres düzeylerinin ilişkisi (Yayınlanmamış Uzmanlık Tezi). Necmettin Erbakan Üniversitesi Meram Tıp Fakültesi Kadın Hastalıkları ve Doğum Anabilim Dalı, Konya, 2014. p. 15-20.

20. Brunton LL, Hilal-Dandan R, Knollmann BC. Goodmans and Gilman's The Pharmacological Basis of Therapeutics. 13th ed. United States: McGraw-Hill;2018. p. 769-887

21. Hughes EJ. Newly discovered physiological effects of oxytocin. Endocrinology \& Metabolic Syndrome 2018;7(3). Doi: 10.4172/21611017.1000288

22. Gimpl G, Fahrenholz F. The oxytocin receptor system: structure, function, and regulation. Physiological Reviews 2001;81(2). Doi: 10.1152/physrev.2001.81.2.629

23. Sara BA, Kurtz LE, Grewen K. Oxytocin and social bonds: the role of oxytocin in perceptions of romantic partners' bonding behavior. Psychological Science 2017;28(12):1763-1772.

24. Pariante CM. Depression, stress and the adrenal axis. Journal of Neuroendocrinology 2003;15(8): 811-812. Doi: 10.1046/j.1365-2826.2003.01058.x

25. Mete S. Stres, hormonlar ve doğum arasındaki ilişki. Dokuz Eylül Üniversitesi Hemşirelik Fakültesi Elektronik Dergi 2013;6(2):93-98.

26. Buckley SJ. Hormonal Physiology of Childbearing: Evidence and Implications for Women, Babies, and Maternity Care (2015). (http://www.nationalpartnership.org/ourwork/resources/health-care/maternity/hormonalphysiology-of-childbearing.pdf) adresinden 23.05.2020 tarihinde erişilmiştir.
27. Yeaton-Massey A, Herrero T. Recognizing maternal mental health disorders: beyond postpartum depression. Curr Opin Obstet Gynecol 2019;31 (2): 116-119. Doi: 10.1097/GCO.0000000000000524

28. Ay F, Tektaş E, Mak A, Aktay N. Postpartum depresyon ve etkileyen faktörler: 2000-2017 araştırma sonuçları. Psikiyatri Hemşireliği Dergisi 2018;9(3):147-152. 10.14744/phd.2018.31549

29. Haight SC, Byatt N, Simas TAM, Robbins CL, Ko YK. Recorded Diagnoses of depression during delivery hospitalizations in the United States. Obstetrics \& Gynecology 2019;133:1216-23. Doi: 10.1097/AOG.0000000000003291

30. Üstgörül S, Yanıkkerem E. Postpartum dönemde kadınların psikosoyal durumları ve etkileyen risk faktörleri. Journal of Academic Research in Nursing 2017;3(1):61-68. Doi: 10.5222/jaren.2017.1012

31. Anokye R, Acheampong E, Budu-Ainooson A, Obeng EI, Akwasi AG. Prevalence of postpartum depression and interventions utilized for its management. Annals of General Psychiatry 2018;17(18). Doi: 10.1186/s12991-018-0188-0

32. Marakoğlu K, Özdemir S, Çivi S. Postpartum depresyon. Turkiye Klinikleri J Med Sci 2009;29(1).

33. Eapen V, Dadds M, Barnett B, Kohlhoff J, Khan F, Radom N, et al. Separation anxiety, attachment and inter-personal representations: disentangling the role of oxytocin in the perinatal period. Plos One 2014;9(9). Doi: 10.1371/journal.pone. 0107745

34. Stuebe AM, Grewen K, Meltzer-Brody S. Association between maternal mood and oxytocin response to breastfeeding. Journal of Women's Health 2013;22(4). Doi: 10.1089/jwh.2012.3768

35. Çatak B, Öner C, Sütlü S, Kılınç S. Where Are We Standing on Postpartum Care? A Cross-sectional Community Based Study. Turkish Journal of Family Medicine and Primary Care 2017;11(4), 256-264.

36. Durmazoğlu G, Serttaş M, Oktay AK, Tatarlar A, Göçmen F, Bezirgan S, Toksoy S. Postpartum Depresyonun Hemșire ve Ebeler Tarafindan Öngörülmesi. Anadolu Hemşirelik ve Sağlık Bilimleri Dergisi 2016;19.

37. Çevik A, Alan S. Ebelere Yönelik Ruh Sağlığı ve Hastalıkları Gebelik ve Lohusalık Dönemi. Alan S, editör. Ruh Sağlığı Hastalıkları Yönetiminde Ebelerin Rolleri. 1. Bask1. Ankara: Akademisyen Kitabevi; 2019. p.102-104. 